\title{
The Universality of Science and Traditional Chinese Medicine
}

\section{A Philosophical Survey}

\author{
Íñigo Ongay de Felipe ${ }^{1,2}[\mathbb{E}$
}

Accepted: 31 May 2021 / Published online: 25 June 2021

(c) The Author(s), under exclusive licence to Springer Nature B.V. 2021

\begin{abstract}
This paper represents a philosophical appraisal of Traditional Chinese Medicine (TCM) from the point of view of the philosophy of science. As it is generally the case with other versions of Traditional Medicine, rather than a coherent research program Traditional Chinese Medicine constitutes an array of various techniques and practices coupled with a diversity of very different speculative doctrines regarding the physiological structure of certain body parts as well as the purported etiology of disease and malfunction. This chapter starts off by describing some of the theoretical assumptions on which TCM relies with the aim of casting light on whether they, alongside the clinical techniques TCM encompasses, can significantly be considered as a scientific theory comparable with that of conventional medicine. In so doing the chapter examines a plurality of demarcation criteria between science and non-science coming from various existing philosophical frameworks old and new. While, as will be shown, a wealth of research based on RCTs (randomized control trials) points out that TCM's degree of effectiveness is low, that is not the point this paper intends to make. Instead of such an empirical criticism, the author sustains a comparably stronger epistemic contention, namely: even if the clinical results of TCM fared better than they actually do, that observation alone would not be a good reason to consider this branch of traditional medicine as a scientifically respectable endeavor.
\end{abstract}

\section{Traditional Chinese Medicine and Evidence}

This paper is a philosophical appraisal of traditional Chinese medicine (in what follows TCM). Among the various aspects of philosophical interest that could arise from an inspection of TCM, attention will be restricted to one epistemic issue alone: the question of its scientificity. Is TCM a set of technical practices grounded on sound scientific theorizing or does it rather constitute a medical techne based on a pseudoscientific theoretical framework? In raising this question, this article does not intend to suggest that the distinction between what is scientific and what is not is to be construed as a dichotomous divide.

Íñigo Ongay de Felipe

Inigo.ongay@deusto.es

1 Faculty of Social and Human Sciences, University of Deusto, Bilbao, Spain

2 Fundación Gustavo Bueno, Oviedo, Spain 
That would be a mistake: as will be shown there are instances at which many grey areas do exist making the decision on whether a particular epistemic practice is scientific a matter of degree. Think also of the explicit or implicit philosophical assumptions underlying a variety of scientific areas of endeavor ranging from quantum mechanics to sociology or indeed biomedicine (Bunge, 1998, 2013; Merton, 1973) and how while non-scientific in nature these philosophical presuppositions might well be necessary for the development of those scientific fields.

The primary scope of the article is epistemic in that it surveys the scientific status of TCM in comparison to so-called Western Medicine (WM). However, this is a matter with educational implications, too. In that regard, let us consider for example the current globalization of TCM practices (Scheid, 1999, Keji and Hao 2003) as well as the explicit presence of this system of healing in educational institutions both in China and in the west. In light of its epistemic status, what should be the place of TCM and other forms of traditional medical systems within current science education? This is a question I will return to at the end of the paper.

First, there is something that needs to be clarified. Although its name might mislead us to believe otherwise, traditional Chinese medicine is not a unified theory accounting for health and disease and giving rise to a coherent set of clinical interventions. Instead, TCM constitutes a rather disunified array of clinical practices and theoretical commitments ranging from acupuncture to herbal medicine to the view of $q i$ (氣) as an all-pervasive form of energy that governs the functioning of the body. All these various elements are largely independent from each other theoretically. Apart from a rather loose family resemblance, what gives them the unity they present stems from both geography and the difference they conjointly exhibit with respect to what is called Western Medicine. Does this mean that one should do better to get rid of the concept of TCM for good and evaluate independently and piecemeal the different components such a misleading label encompasses? The answer to that question is no.

Here is why: even though the unity between the various practices and theories that fall under TCM might seem theoretically flimsy, it is still a kind of unity. The fact that TCM includes a combination of theoretical assumptions, philosophical views, therapeutical practices, and ideas on diagnosis which are distinctively Chinese in their origins may not be relevant scientifically but is relevant in other ways: for example, socially, historically, or ethnologically. In that respect, TCM is no different from other examples of traditional medicine or ethnomedicine such as Australian Bush Medicines, Ayurvedic Medicine, Iranian Traditional Medicine, or African Traditional Medicines (Aramesh, 2018; James, 2018; Mahomoodally, 2013; Oliver, 2013), which also encompass an assortment of very heterogeneous tenets whose degree of theoretical cohesiveness is similarly low.

However, this paper will ascertain the extent to which TCM can be considered scientific. For that purpose, it may be worthwhile to keep in mind that the diversity of doctrines and therapeutical methods that TCM includes may happen to stand on different epistemic footings. It is not written in bronze that all the aspects of TCM should always stand or fall together with regard to their scientific status. That doesn't need to be the case although they may also do so depending on the demarcation criteria between science and non-science employed.

TCM constitutes a disunified endeavor, but there is another aspect needing attention here. As Michael Matthews (2019) has shown convincingly the ontological cornerstone all the different aspects of TCM rely on is the idea that the universe is permeated by an all-encompassing (and indetectable) vital energy ( $q i)$ which dominates the human body in all its functions regulating respiration, nutrition, body temperature, blood flow, defense 
against pathogens, and a number of other processes. Although there are different versions of TCM with slightly distinct ontological underpinnings, a familiar idea (Liu 2012) is that $q i$ comes in a variety of forms depending on the bodily function it applies to. There are supposed to be four main types of organic qi (pectoral qi, nutritional qi, defensive qi, and parental qi). In any event, the contention goes that although qi as a universal force does permeate the human body in all its systems, as indeed it does permeate the whole universe, it tends to concentrate in certain anatomical pathways called meridians (Langevin \& Yandow, 2002; Matuk, 2006).

While in this framework the body is understood as a harmonious and coherent totality of a variety of physiological systems, the meridians are the channels that give unity to the whole. It is precisely through these linking points that the qi becomes more readily accessible and it is on them that acupuncture practitioners operate to manipulate the flux of qi by employing a variety of techniques including the use of needles, finger pressure, cupping, and so on. What makes such interventions by the practitioners therapeutically important is that according to the existing theories about etiology and pathogenesis in TCM, disease arises when an imbalance exists between the different energies of the human body through qi excess or deficiency or alternatively when an excess of air, dryness, heat, or cold occurs either due to the influence of the environment or for entirely internal reasons. In light of these etiological ideas, the proponents of TCM claim that in the face of a given organic condition, manipulating the meridians leads to a correction of such forms of imbalance and thus the restoration of health.

Now, quite apart from the question of whether there is evidence for such an account of the body or for the set of clinical methods that stem from it (an issue the paper will return to shortly), there is another aspect worth considering in relation to the idea of qi.

Michael Matthews (2019) argues that one feature of this concept should give us pause when considering its scientificity. That aspect is the undetectability of qi the way it is defined in some versions of TCM. Matthews notes that while many theoretical entities in science are notably difficult to grasp or measure, it is not a good signal when a concept is defined as being in principle impossible to grasp or measure. This should be taken as a prima facie indicator of non-scientificity, as shown by a cursory inspection of the epistemic misfortunes of many other similarly inscrutable constructs from the élan vital of the vitalist philosophy of life to the unconscious mind of Freudian psychoanalysis (but see Talvitie, 2009; Northoff, 2012; Cieri \& Esposito, 2019 for contemporary discussion in the context of current psychodynamic neuroscience to the effect that current neuroscience may vindicate some of the original insight behind Freud's psychoanalysis). That is a good point, but notice that even if this consideration about undetectability makes TCM suspicious of nonscientificity, is not by itself enough to settle the question definitely since there exist other less mysterious accounts of the notion that conceive of qi as part of the natural world. Such conceptions tend to construct qi as a type of energy which is traceable from its effects on different physical systems.

To see if such an indicator is something more than a bad augury, it needs to be considered what the evidence indicates about the different therapeutical branches of TCM. Ever since the advent of evidence-based medicine (EBM), it has become customary to affirm that clinical decision-making as well as public health policies should be based on the best evidence available. According to the same framework, it has further become standard to think that the best evidence at hand comes from clinical assessment alongside data sets obtained by a multiplicity of randomized control trials (RCT) and in particular double-blind randomized field test (DBRFT) (Sackett, 1997, Masic, I. Miokovic, M and Muhamedagic, B., 2008). This looks like a sound line of action in making decisions about 
clinical matters and designing public health policies even if at times those decisions need to be made in scenarios where little evidence is available as the current COVID-19 pandemic shows aplenty (Ioannidis, 2020).

To see why the central idea motivating EBM is sensible, it might be useful to recall a basic epistemic point brought about by evidentialists. Broadly construed, evidentialism is the thesis that evidence represents the only basis on which it is reasonable to justify one's doxastic attitudes about what to believe and what to disbelieve (Feldman \& Conee, 1985; McCain, 2014). There abound objections against this rather restrictive epistemic policy, and some of them might be right but that is not a debate I want to consider in this context. Instead, let us establish the largely uncontroversial suggestion that evidence does constitute one of the bases on which it is reasonable to construct one's doxastic attitudes. Although there might be controversy about the point as well, I hope that the reader agrees that this being so it follows that empirical evidence is one of the bases on which it is reasonable to make decisions, too.

When taken at its face value, the idea of integrating clinical expertise about individual cases with the best external evidence obtained with systematic research feels intuitively at home with the sort of weak evidentialism the previous paragraph has described. However, although this sounds about right, such a sensible epistemic advice stands in need of clarification. The rationale for saying so is twofold. First, there is the familiar notion that the process by which evidence is assessed in science is oftentimes contrastive. This means that observational evidence rarely confirms one hypothesis once and for all, what it normally does instead is something way more modest, namely to favor one hypothesis over another by making the former more likely than the latter (see Fisher, 1922; Hacking, 1965). There is a second related consideration worth examining here: the fact that the assessment of evidence is inherently contrastive also implies that it is a mistake to say that evidence rules out a hypothesis altogether. This is again not a realistic characterization of how scientists operate.

What scientists do is measure the extent to which the observations at hand make different hypotheses more or less likely true. The likelihood of some hypotheses may at times turn out to be dismayingly low (in comparison to others) given the evidence available. When this is the case, it is usually good advice to abandon them but that is not the same with saying that evidence declares them false conclusively. While the former is a reasonable scientific policy to adopt, the latter is a fallacious line of reasoning to eschew. For much the same reason, it would be misguided to assume that one given event is impossible just because it has an extremely low probability to occur. After all, it is a trivial truism in probability theory that very rare events sometimes happen much like very improbable hypotheses may sometimes turn out to be true.

Those considerations are fine as far as they go, but they alone fail to settle the issue at hand. What does the evidence indicate about the clinical effectiveness of such practices as those of acupuncture or Chinese herbal pharmacology? The answer to that question is largely negative: against some inconclusive reports to the contrary for the cases like eczema, fibromyalgia, or some forms of painful menstruation (Kang, 2018, Akpinar and Karatay 2018, Li et al., 2020, Yang et al., 2020), most of the available metanalysis (Ernst, 2006, Hard to swallow, 2007, Anh et al. 2008) doesn't favor the purported therapeutical efficacy of TCM for conditions as diverse as HIV, angina hemorrhoids, different forms of cancer, and so on. Furthermore, existing double-blind studies are largely inconclusive about the therapeutic efficacy of acupuncture for a variety of conditions (Gaw et al., 1975, Mendelson et al. 1983, Vase, 2015 This doesn't mean that no patient is ever reported to get better after being exposed to a TCM based treatment (it would be after all extremely 
surprising that such an unequivocal result should ever obtain as there will be always people reporting all kinds of experiences). What this implies is something more nuanced: when it comes to an ample range of conditions, patients of TCM practitioners don't get better more often after being treated with therapies such as die-da (跌打), cupping, and qigong (氣功) that the alternative null hypothesis would make us expect (Colquhoun \& Novella, 2013).

\section{What if the Evidence Would Dictate Otherwise? The Notion of Evidential Success Re-considered}

Thus far, the low evidential basis for the clinical effectiveness of TCM has been considered. In light of the modest form of evidentialism presented in the previous section, such a stumpy empirical support seems to be a prima facie legitimate reason to think that other things being equal TCM is not a reasonable guide for action. But, things could have turned out differently. To understand why this point is important, it is helpful to consider a counterfactual situation. Suppose that practices such as acupuncture or herbal Chinese pharmacotherapeutics fared better evidentially than they do. The readers can imagine that evidential support to be as strong as they please. Would that confer scientific legitimacy on TCM and its subrogated clinical applications? Not necessarily.

To see why this is so let us consider an epistemic point about the concept of scientific explanation made by Hempel (1965) among a variety of other philosophers of science (though see de Regt \& Gijsbers, 2017 for discussion). It is widely recognized that scientific theories aim to provide explanations of the evidence at hand. While there is much debate on what it means to explain something, a broad consensus exists to the effect that a theory cannot be explanatory if that theory is not true. This is not to say that a false theoretical account would lack explanatory power should it be true. Of course, it wouldn't, but that counterfactual consideration says nothing about the actual explanatory status of theories that are known to be false.

To show how this is relevant to the question at hand, suppose that acupuncture was demonstrably effective in helping patients suffering from an array of conditions to improve. Granted those would be good news for these patients. Given the technical nature of the discipline, such effectiveness would also be good news for the goals of acupuncture, too. However, instead of falling into the allure of evidence, it would be epistemically wise to pause and reflect on the following: the theory of the meridians that acupuncturists utilize to "explain" why their practices produce their purported results is fantastic in nature in that it does not cohere with any known principle of current human physiology. In other words, there are no reasons to believe that the meridians exist, and thus, they can hardly provide an explanation of the effectiveness of acupuncture.

What has been noted about explanation can be captured also by invoking a standard distinction in probability theory. Following the steps of Ronald Fisher (1922), it has become customary for philosophers of science to distinguish between the likelihood of an observation given a hypothesis and the independent probability of that hypothesis prior to the observations.

An example from Elliott Sober (1999) may clarify how this distinction is relevant to the case in point. To say that the weird noises you happen to hear while in the solitude of your home are likely to obtain. If there is a bunch of gremlins bowling in the attic is one thing, it is quite another to affirm that the hypothesis that there are actually gremlins bowling there is probable. The first of these statements may seem sensible given both the technical sense 
of the concept of likelihood and the way gremlins are depicted in the movies. The second one, which refers to the prior probability of the hypothesis itself, is simply outlandish in light of all that is known about the (in)existence of such creatures.

Although the abovementioned asymmetry pertains to probability, there is a relevant analogy to be drawn here with regards to the explanatory power of the theory of the meridians and the effectiveness of acupuncture therapy. It might well be the case that the theory of the meridians would, if true, explain the evidence for the effectiveness of acupuncture, but whatever the case the fact still remains that the theory is sure to be false in light of all that we know about human physiology.

Although the falsehood of the theory of the meridians is a strong consideration by its own right, there is a second comparatively weaker point to take into account. While it is conceivable that the friends of TCM might disagree, it is unclear how such a theory, even if it were true, would be explanatorily relevant to the evidence for the therapeutic effectiveness of acupuncture. The reason why this is so is because the internal mechanism provided by this theoretical account is too vague to signal a clear causal pathway accounting either for the etiology of the various diseases it identifies or for the efficacy of the treatments it proposes. If, as Salmon (1984), Woodward (2003), and Lombrozo and Vasilyeva (2017) have argued, part of what a scientific explanation involves is to establish an intelligible causal process linking the theory to the evidence, it follows that the theory of the meridians fails to explain its own evidential success given the (very) nebulous way in which the purported inner-causal mechanisms that theory describes are defined.

There is a further ramification to keep in mind. The paper has argued that the theory involved by TCM fails to account for its own purported success. Even if this far that success has been constructed in the form of a counterfactual proposition about the evidential basis for TCM, it is time now to take the counterfactual away under certain plausible definitional assumptions. If the notion of success is defined in a sufficiently broad manner, there is no doubt that acupuncture and a variety of different forms of Chinese herbal therapy are socially successful. After all, these practices have endured for long periods of time and still continue to do so, which would expectedly not happen if a significant number of patients didn't keep resorting to them (presumably because they feel better upon utilizing these procedures).

As has been noticed the theory of the meridians is far from providing an intelligible explanatory account of this admittedly modest form of social success, but if so, it is worth asking what would do the explaining instead. The answer to that question may seem surprising to some ears and yet it resonates aloud in the present context: modern international medicine, as a set of clinical practices based on experimental and theoretical work in an array of scientific endeavors (from biochemistry to physiology), has many theoretical mechanisms at its disposal, which allow for the observation that some TCM patients may recover from their conditions. The familiar placebo (or nocebo) effect is but one of a long list of well-understood principles ranging from spontaneous remissions of various diseases (Challis \& Stam, 1990; Cole, 1976; Everson \& Cole, 1968) to classical conditioning of the immune system (Vits, 2011) or to voodoo deaths (Cannon, 1942; Sternberg, 2002) and other psychosomatic effects (Fava \& Sovino, 2000, 2010; Lyketsos et al., 2006).

It is not modern international medicine alone; however, other areas of concern in the social sciences - from sociology to psycho-sociology to ethnology — may also help account for the salient fact that the enterprise of TCM does recur socially notwithstanding its illfounded and rather mythological commitments. The take-home message that this analysis entails has to do with a noticeable explanatory asymmetry between WM and TCM which paves the way for an inference to the best explanation: while WM can explain TCM's 
success in a way that really makes intelligible why such a success obtains, TCM in contrast fails to do the same. This dissymmetry signals one specific aspect at which WM shows superiority over TCM.

\section{TCM and the Problem of the Demarcation Criterion}

An explanatory asymmetry holds between TCM and WM in that there is at least one thing that WM but not TCM can do. Whereas TCM and the ontological assumptions about the world on which it is based is not in the position to provide an explanation of its own alleged therapeutic success, WM can do that explaining by appealing to a whole array of scientific theories. The asymmetry in question signals that there is at least one relevant epistemic respect at which TCM and WM stand on fundamentally different epistemic footings. One way to reflect on the consequences of that difference between both schemes is by examining how a much-debated philosophical problem pertaining to the nature of science bears on TCM and its relations to WM. Philosophers of the science of different persuasions have long disagreed about what distinguishes science from non-science. Rather than rushing to take sides in such a debate, the goal here is to consider how a variety of alternative candidates to serve as demarcation criteria may help to think clearly about how TCM is different from WM.

As a part of their anti-metaphysical campaign, the Vienna Circle insisted that meaningful statements should be verifiable in principle. Although the neo-positivists (Ayer, 1936; Carnap, 1936; Schlick, 1936) originally presented their principle of verifiability as a criterion of meaning pertaining to all type of propositions, there is general agreement that so construed the proposal is flawed on a multitude of grounds (Hanson, 1958; Hempel, 1950; Ingarden, 2018; Popper, 1959). A natural move in the light of that failure would be to interpret verifiability as a criterion demarcating scientific from not scientific statements instead of as a signal of semantic meaningfulness. Unfortunately, that wouldn't work either. Part of the reason why such a use of verifiability goes astray was appropriately captured by Karl Popper (1959) when he noticed rightly that scientific theories typically involve law-like statements of universal scope that cannot be conclusively verified no matter how abundant the empirical evidence scientists may ever happen to marshal in their favor. Instead of such an overly ambitious goal, Popper turned his attention to falsifiability as a much more modest and feasible objective for scientists to undertake. Here Popper is asserting that it is the property of being falsifiable in principle rather than the comparatively more demanding principle of verifiability that really distinguishes scientific statements from their non-scientific counterparts whether of metaphysical or pseudoscientific nature.

Popper is right to notice that the universal laws with which many scientific theories are fraught are not verifiable, but he is wrong about the prospects of his own alternative of falsifiability. What falsificationism in its original version missed is that even if scientific laws are not conclusively verifiable in virtue of their unlimited scope, they aren't falsifiable in a similarly conclusive fashion either. Pierre Duhem (1914) and William van Orman Quine's (1951) convergent albeit different points show why.

As Duhem and Quine independently noticed, law-like statements only entail empirical consequences when they are taken in conjunction with a network of background hypotheses but not when they operate on their own. It is worthwhile to recognize that this is a point that Popper did subsequently acknowledge in later publications (Popper, 1974a, 1974b). 
One consequence of this holistic view of how theories are empirically assessed is that when evidence runs against what a given theory predicts, it always remains an open possibility for scientists to manipulate indefinitely numerous sets of nodes within the net so that any statement of their choice stays safe. In line with such a holistic view of the relationship between theory and evidence, Irme Lakatos (1978) also argues that law statements within scientific theories are indefinitely resistant to refutation insofar as they are protected by a vast belt of auxiliary hypotheses. This is again a point Popper granted later leading to a final version of his theory where the emphasis is put on determining which amendments of a given theory are purely "ad hoc" and which are legitimately scientific.

The fact that scientists may at any given time decide to modify a theory so that any of its statements is protected from falsification shows that in practice falsifiability is not enough to discriminate science from non-science. All theoretical constructs, whether scientific or not, can be made immune to negative evidence provided that the researcher decides to amend the right auxiliary hypotheses. This talk about the possibilities scientists may decide to explore when overhauling a theory does not mean that the question at hand solely concerns the psychology of the researcher. What Duhem and Quine's thesis points to is rather a logical characteristic of the relationship between empirical evidence and the theoretical networks: the latter can be indefinitely amended to accommodate the former. It is true that proceeding to amend the theories in this way, in particular when it involves furnishing ad hoc modifications anew may perhaps seem like a psychologically suspicious rescue operation of a pet theoretical construct in bad empirical shape but that doesn't mean that those amendments are either logically faulty or heuristically illegitimate. In rejecting naïve forms of falsification, Irme Lakatos (1978) advances that it is standard practice in the history of different scientific disciplines to modify research programs so that their hard cores are allowed to survive a number of increasingly demanding empirical tests.

The previous remarks are problematic for falsifiability, but there is a further challenge to consider. Many branches in a variety of scientific endeavors (from evolutionary biology to epidemiology and from quantum mechanics to thermodynamics) involve references to processes of a scholastic and probabilistic nature that-as statisticians routinely admonish-don't allow for a complete falsification in the form of a Modus Tollens argument. Popper (1959) thought that it is a distinctive mark of non-scientificity that a statement should be made compatible with any conceivable combinations of observations but in fact, that is a feature of any probabilistic statement in many areas of science. After all, probabilistic hypotheses don't declare events impossible, what they do instead is to affirm that certain states of affairs are more or less unlikely to occur and then leave it open whether or not they will take place. The idea driving falsificationism is that scientific statements are refuted by the occurrence of those empirical events they prohibit but that is fundamentally at odds with a multitude of scientific fields where law statements happen not to prohibit any event.

The previous gloss on the Duhem-Quine thesis and the logical implications of probability were meant to let the reader see why it is mistaken to think of falsifiability as a valid demarcation criterion. Notice however that it would be equally misguided to read too much into this debunk of naive falsification. Asserting that scientific statements are often impossible to falsify conclusively is correct but does not mean that no hypothesis ever is even weakly falsifiable. In order to see why, it is worthwhile to take a look at what scientists do in their day-to-day practice: the history of science is full of episodes where false ideas get dismissed by scientists after the empirical consequences they entail fail to obtain observationally. To say that these culs-de-sacs are only weakly refuted in the very demanding sense that they cannot be discarded as wholesale impossible is true but heuristically irrelevant since this sort of logically weak falsifiability is often all it takes to dispense with them 
forever. In that regard, it is safe to assume that (technically) weak falsification is frequently strong enough from a practical point of view.

Does the trivial fact that some scientific hypotheses are in fact weakly falsifiable allow for a demarcation criterion indicating what is wrong with TCM? Perhaps so but I doubt it. My reason to the doubt of the soundness of this possibility is twofold. Firstly, if being (weakly) falsifiable was to be taken to represent a sign of scientificity, that would seem to imply the counterintuitive conclusion that TCM is a legitimate-albeit false-branch of scientific medicine as the efficacy of TCM clinics is (weakly) falsifiable and has been (weakly) falsified repeatedly by an overwhelming series of RCTs. Notice that such a consequence is undesirable as it suggests that a plentitude of other bizarre speculations-from flat earth theories to the existence of the Loch Ness monster-would need to be deemed scientific, too. This is outlandish.

There's a further and more general reason for denying that weak falsifiability constitutes a good demarcation criterion. It is true that scientific statements can be dismissed after empirical falsification and it is further true to say that many are actually so dismissed routinely, but there is nothing unique to science in that. The same is true of many mundane hypotheses pertaining to our daily life which the layperson is prepared to abandon in light of empirical evidence to the contrary. Although the very Popperian process by which conjectures are confronted with refutations is a situational logic (Popper, 1957, 1963, 1972, 1974a, 1974b) that applies to many aspects of scientific reasoning, it is hardly a defining characteristic of it. It is rather a general scheme which both scientific and non-scientific human practices pertaining to the natural world share in common.

In the face of the combined failure of both verifiability and falsification, one might well be tempted to dismiss out of hand the prospects of any formulation of the demarcation criterion. Larry Laudan (1983) famously advocated the demise of the demarcation problem. Here's a good formulation of what Laudan is after:

The evident epistemic heterogeneity of the activities and beliefs customarily regarded as scientific should alert us to the probable futility of seeking an epistemic version of a demarcation criterion. Where, even after detailed analysis, there appear to be no epistemic invariants, one is well advised not to take their existence for granted. But to say as much is in effect to say that the problem of demarcation - the very problem which Popper labelled 'the central problem of epistemology' - is spurious, for that problem presupposes the existence of just such invariants. In asserting that the problem of demarcation between science and nonscience is a pseudo-problem (at least as far as philosophy is concerned), I am manifestly not denying that there are crucial epistemic and methodological questions to be raised about knowledge claims, whether we classify them as scientific or not. Nor, to belabor the obvious, am I saying that we are never entitled to argue that a certain piece of science is epistemically warranted and that a certain piece of pseudo-science is not. It remains as important as it ever was to ask questions like: When is a claim well confirmed? When can we regard a theory as well tested? What characterizes cognitive progress? But once we have answers to such questions (and we are still a long way from that happy state!), there will be little left to inquire into which is epistemically significant. (Laudan, 1983, 124)

Note that if Laudan is correct in his debunking of the problem of demarcation, the objective of examining whether TCM is scientific would need to be declared an irrelevant goal. In denying that it makes sense to scrutinize the scientific credentials of TCM or any other form of epistemic enterprise, Laudan is not claiming that it is impossible or irrelevant 
in general to examine the empirical validity of particular knowledge claims. Rather than endorsing such a wholesale negationist approach, what he is saying is that while that empirical examination of specific claims is a doable and possibly important objective to adopt, it would be in vain to go on to raise up a more general problem of demarcation between what is scientific and what is not: determining the scientificity or lack thereof of an empirical claim is just an irrelevant objective.

Laudan is clearly right that science is too complex and pluralistic an activity to be characterized easily by invoking one single necessary and sufficient cutoff criterion of scientificity. This paper has already argued that rather than representing a clear-cut dichotomy, the distinction between science and non-science is oftentimes a matter of degree. Notice however that this alone does not suffice to jump to the hasty conclusion of declaring the demarcation problem a pseudo-problem. As Michael Matthews (2019) has shown this further move on the part of Laudan ironically conflicts with some of the positions he endorsed elsewhere (Laudan, 1981). As Steve Fuller (1985) points out saying that there is nothing at stake in distinguishing science from non-science also contrasts with the non-trivial and constant social role which science has played.

Notice further that this blunt demise of the demarcation problem also fails to capture a trivial fact of our ordinary epistemic lives: although ambiguity abounds in certain grey areas, it is relatively easy to identify clear-cut examples of both scientific and non-scientific activities at both extremes of the epistemic spectrum. Consider on the one hand the case of thermodynamics and on the other such clearly non-scientific areas of concern as voodoo or astrology.

The difficulty of separating science and non-science in a variety of less unequivocal cases doesn't mean that the goal of singling out what is epistemically different about science is an unattainable or misdirected one, all it implies is rather than we'd better refine our epistemic tools before addressing that task. Laudan's argument misses that point because it throws the baby out with the bathwater and thus commits the fallacy of proving too much.

\section{Beyond the Demise of the Demarcation Problem: Mario Bunge and Massimo Pigliucci on Scientificity and Pseudoscientificity}

Even though Larry Laudan's argument for the futility of the demarcation problem is fallacious, his point about science and non-science being continuous activities is a good one. One way to capture what Laudan gets right and where he goes wrong is by noticing that while it is mistaken to approach the problem at hand by looking for dichotomous differences, whether based on verification or falsification, from that alone, it doesn't follow that there are no differences at all. The situation at hand is aptly captured by John Dupré (1993) when he argues that what all the branches of science have definitionally in common is the vagueness of a Wittgeinstenian family resemblance rather than one single property to be uniquely characterized. That might be true, but as John Dupré notes, mistaking vagueness for inexistence amounts to forgetting that however diverse the candidates for the demarcation criterion may be in the different theoretical accounts and notwithstanding the disagreement on some specific cases, there seems to be broad consensus on which particular activities count as clearly scientific and which ones don't.

Sven Ove Hansson has it right when he writes: There is widespread agreement for instance that creationism, astrology, homeopathy, Kirlian photography, dowsing, ufology, ancient astronaut theory, Holocaust denialism, Velikovskian catastrophism, 
and climate change denialism are pseudosciences. There are a few points of controversy, for instance concerning the status of Freudian psychoanalysis, but the general picture is one of consensus rather than controversy in particular issues of demarcation. (Hansson, 2017)

In light of such a general agreement (Hansson, 2009a, 2017) regarding the extremes of the spectrum, it would be a form of the familiar Sorites fallacy to dismiss out of hand any existing general difference between science and non-science due solely to the inherent vagueness pertaining to certain cases in point. There are after all myriads of other equally vague predicates we don't feel inclined to get rid of in so easy a fashion. To see how to construct an alternative and more nuanced account this section will turn the reader's attention to the proposals of two philosophers of science: Mario Bunge $(1982,1985,1991)$ and Massimo Pigliucci (2013, Pigliucci \& Boudry, 2013).

Although their approaches differ in a variety of details, there is something important Bunge and Pigliuci agree on. Their concurrence has to do with the negative observation that no single criterion has so far succeeded in providing a uniquely valid characterization of what distinguishes science from non-science. However, they both also go on to conclude that from such a failure of a variety of single criterion treatments it needn't follow that there is no criterion at all. Instead of endorsing such a nihilistic conception, what Bunge and Pigluicci among a plurality of other authors (Kitcher, 1982, Hansson, 1983, Ruse, 1996, Mahner, 2013, Fernandez Beanato, 2020) maintain is that a multiplicity of criteria is called for here.

In a sizable number of contributions devoted to the topic at hand, Mario Bunge has offered a 10-tuple list of desiderata that cognitive claims and epistemic practices must honor in order for them to be categorized as scientific. This 10-tuple includes several items ranging from the existence of a community of appropriately trained researchers equipped with recognizable public means of information exchange to the reference to an epistemic domain (D) composed of real processes and events in the natural world. On Bunge's account of science, it is equally important that coherence should exist between the knowledge claims to be discerned and a body of well-confirmed knowledge (K) about D as well as an appropriate background (B) of data, theories, and hypotheses about other domains of the world or a set of formal mathematical and logical methods (F) to be utilized. Other features that are also recognized as being relevant in this scheme include the goal of discovering laws or confirmed hypotheses about $\mathrm{D}$ or the presence of a general philosophical background which includes an ontology of real things, a critically realistic sort of epistemology, and the abidance to a certain type of value systems orientated to the search for the truth about D.

Now, while it is doubtful that so defined all these characteristics are in fact equally relevant, Bunge's enumeration is persuasive. That doesn't mean that the list is exhaustive. There are other items that might be needed also. For example, some philosophers may want to add to Bunge's reconstruction a minimalistic reference to the set of epistemic and nonepistemic values that scientists usually uphold (Merton, 1942; Rudner, 1953), although the case could be made that these are already distributed throughout the criteria in Bunge's list.

More recently Massimo Pigliucci (Pigliucci, 2013, Pigliucci \& Boudry, 2013) has provided a converging treatment of the demarcation problem. Pigliucci starts off by noticing that the idea that a dichotomous boundary between science and non-science is faulty shouldn't lead us to believe that there is no demarcation. In the stead of nihilism, he advances that scientific knowledge, much like other similarly complex categories such as 
that of biological species or biological individuals (Pigliucci 2002, 2013; Ongay de Felipe, 2020), is best characterized by employing some formal tools issuing from fuzzy logic.

In particular, Pigluicci distinguishes a diversity of clusters of more or less scientific areas of endeavor ranging from HIV denialism or string physics at one end of the continuum all the way to evolutionary biology or particle physics at the other. These are all disciplines that vary in their respective degrees of both theoretical coherence and strength and empirical support, the two threads that Pigluicci contemplates as distinguishing science and non-science. Cases in points deserving specific attention could be obviously multiplied ad libitum here (from psychology to sociology to history or climate science) but let us suffice to say the upshot of this analysis resonates clearly that while scientificity and non-scientificity are predicates that come in degrees there are clearly defined examples of both categories.

\section{Why TCM Is Not Science and Why It Matters}

Unlike several single-criteria accounts, Bunge and Pigluicci's concurring frameworks have the versatility of separating science from non-science as well as establishing a set of diverse categories within non-science itself: from non-scientific reliable knowledge (like our day-to-day empirical claims) to pseudoscience or science-denialism. That feature is important but there is more: they also possess another advantage to be noted. They help us think clearly about the reasons why TCM is not scientific. To say that TCM lacks evidence does not solve the issue as it seems very dubious that some clinical practices within TCM have no evidential support.

But, for a second reason, resorting to evidence isn't good enough. Lakatos asserted that: A theory may be scientific even if there is not a shred of evidence in its favor, and it may be pseudoscientific even if all the available evidence is in its in favor. (Lakatos, 1981, p.117)

This remark is provocative but goes wrong in that it suggests that the question of the scientific or lack thereof of a given theory can be ascertained without reference to the empirical support that theory exhibits. Interpreted in that way, Lakatos' remark goes too far. A problem is that although evidence is not the only thing that matters, it is clearly one of them. These other things include some of the epistemic virtues demanded by Bunge's multicriteria reconstruction of the demarcation problem. In particular, there is the need for a certain degree of coherence between the theory in question and a well confirmed and theoretically rigorous body of background knowledge pertaining to the same or other domain of facts. Now, even if it is true that TCM and the clinical methods that stem from it presuppose a theoretical conception of the body, that theory is ambiguous to such an extreme that different practitioners of acupuncture and other therapeutic methods regularly disagree with one another about their diagnosis or clinical advice.

What is more, the theoretical understanding of the functioning of the human body that TCM conveys as well as its conception of the etiology and nature of various diseases and the way to treat them is fundamentally at odds with modern physiology, histology, and pathology. The reason for this theoretical disconnect between TCM and modern international medicine is the fact that many of the theoretical concepts of TCM (from the notion of qi to the meridians or to xue (血瘀) or to the principle of the eight excesses and so on) aside from being notoriously hard to operationalize, fail to find any equivalents in our 
modern scientific understanding of how living systems function and misfunction. All in all, the problem with TCM does not only pertain to its evidential basis, which is low though not inexistent. The trouble has to do with the precariousness of the connection between its rather incoherent theoretical assumptions and the broader state of the art in the different pertinent realms of current science.

Considering modern international medicine (MIM), the reader might be surprised to hear that it is not a science either. To counter the bafflement, consider the practical nature of the goals of medical activity. In that respect, different from biology and much like engineering, MIM represents a technological activity (Hansson, 2009b; Vos \& Willems, 2000) that is based on an ample variety of scientific disciplines ranging from histology to microbiology, from molecular biology to biochemistry, physiology, biophysics, and statistics. In that respect, while the medicine is not a science given the practical ends it intends to fulfill, that does not mean that we have to deem it pseudoscientific. If the term "scientific" is taken as an adjective, MIM (but not TCM) is scientific because it operates in continuity with the results of scientific research in a diversity of domains.

Such a continuity between medicine and an array of areas of concern in the natural sciences has another consequence that is worth considering here. Notice that even though it is historically true that many of those disciplines were first developed in the Western world and then introduced to the east, that truth about the history and the geographies of science says nothing of epistemic interest about the validity of the laws of nature scientific research contributes to establish. In that regard, it can be said that in spite of the confusion its misnomer may induce at times, there is nothing particularly western about Western medicine for the law-like statements it is based upon are universal in their scope.

There is another interesting asymmetry with respect to TCM to take into account here. While WM is not western except in name, TCM given its ontological foundations is really specifically Chinese insomuch as it is grounded on assumptions that come from worldviews closely related to Feng shui as well as classical Daoism and Confucianism (Matthews, 2019). It is true that whatever the origins of TCM in its present state of development is usually presented in a geographically neutral manner. However, the assumptions on which TCM is based make no theoretical sense out of the cultural and ontological framework from which it derives and runs against our modern understanding of the anatomy and physiology of biological organisms.

The analysis so far does not say that TCM and the sort of treatments it inspires has no efficacy in curing certain conditions. It would be extremely surprising that such a longenduring cultural practice should have been socially reinforced for an extended period of time in the absence of any success in delivering positive results for their adherents. If that were the case, the endurance of TCM would be literally inexplainable. Conversely, notice further that the analysis also doesn't deny that interventions based on WM may sometimes have negative repercussions for the health of the patient as the well-researched phenomenon of iatrogenesis shows.

Given what is known about cultural evolution, it is way more likely that the empirical benefits of TCM, inconsistent and occasional as they may be, should have resulted in the practices in question surviving within a cultural context where science-based medicine was not available. Given the ambiguity of TCM diagnosis and nosology, there might well be cases where the purported disease comes as a social delusion rather than as a somatic condition, and then of course TCM and not WM would be a viable practical solution (albeit for a largely delusional problem, see Bueno, 1993). Likewise, there is nothing inherently irrational in the use of TCM. On the contrary, in the light of the nuanced form of evidentialism defended in the first section of this paper, it follows that it may well be reasonable to 
resort to TCM (or any other version of traditional medicine for that matter) where there is no alternative of better epistemic credentials to be found. After all, TCM sometimes works empirically even if not for the reasons TCM proponents believe.

What the analysis suggests is that all the empirical cases where the effectiveness of TCM can be established must be principally explainable and replicable by appealing to the laws of ordinary physiology, immunology, histology, pathological anatomy, and various other disciplines that WM refers to. That is another sense in which WM alongside the branches of science it is based on is universal in character (Bueno, 1993). WM is universal precisely because the sphere of its applicability does not restrict itself to explaining its own therapeutical efficacy but expands to the efficacy of the different forms of alternative and traditional medicine, too. This is significant because the spurious causal connections that the theory behind TCM purports to describe don't explain the symptomatic improvement a patient may report after having been treated by an acupuncturist. But, the laws governing the placebo effect and numerous other physiological and psychosocial mechanisms (from illusions of causality or illusory correlations to selective memory or confirmation bias) may do so.

The placebo effect is not an arbitrary occurrence but a process of classical conditioning of the immune response of an organism possessing very complex psychological features. Also, it is conceivable that some remedies taken from Chinese herbal medicine may work at times when used to treat certain conditions. But to the extent that they do, that will be attributable to the chemical properties of their active principles and not to the power they allegedly exert over the lack or the excess of qi. This is because while science has little use for the concept of qi, the chemist and the pharmacologist can understand and explain the chemical reasons why a given product brings about an effect on an organism. They can also isolate that active principle and use it in the design of new drugs to be prescribed in WM. Notice that the same isn't true about the TCM clinician, who may perhaps know what herbal compounds work empirically in causing a somatic disorder to improve while being entirely wrong about the real processes by which the improvement is produced.

\section{Concluding Comments}

At the beginning of Anna Karenina, Leo Tolstoy writes that "Happy families are all alike, each unhappy family is unhappy in its own way." As multicriteria treatments of the demarcation problem show, there is likewise more than one way in which a social activity can diverge from the standards of scientificity. Advocates of evidence-based medicine argue that the low evidential support attained by TCM in RCTs should make us suspicious of its scientific status. This may suggest that lack of evidence constitutes the main reason leading TCM to disqualify as a scientific activity. This suggestion is mistaken. Although evidence is important, to fully see what else is wrong about TCM, one needs to open the black box of RCTs and consider the causal mechanism that a given theory proposes to explain what sort of evidence should obtain. That is what motivates Nancy Cartwright $(2007,2011)$ to assert that even if RCTs are often regarded as the golden standard for nowadays biomedical science, they also present serious limitations when it comes to their broader epistemic status.

This paper has argued that except for a few clear-cut cases situated at opposing ends of the epistemic spectrum, the difference between science, non-science, and pseudoscience comes in degrees. This means that in most cases one single criterion wouldn't be enough to 
shed light on why a given epistemically suspect practice fails to qualify as scientific. That is also why flexibility is called for here and accounts based on a multiplicity of different criteria are needed. The reason why these considerations are important when it comes to the case in point is that when judged from the angle of the evidence in its favor, TCM cannot be disqualified as non-scientific since that evidence, while low, isn't inexistent. However, as multiple criteria accounts show, evidence alone is not the only thing to consider. As has been demonstrated here, when considered from the point of view of its theoretical coherence as well as the compatibility of its central tenets with various domains of science, TCM is a mess (Eigenschenk et al., 2020). This said, however, I would like to close this paper on a more practical note about TCM and its diverse clinical ramifications as a social institution.

The sort of evidentialism promoted by EBM implies that other things being equal, it is not reasonable to employ TCM in a society that possesses other medical alternatives with better scientific credentials. This consideration is sound, but the reason why the ceteris paribus clause of the previous remark has been italicized is because there is nothing inherently irrational about resorting to the so-called traditional medicines in cultural contexts where science-based medicine is historically absent. The usage of TCM becomes unreasonable contrastively when compared to other clinical practices which, aside from marshalling better evidence in their favor, cohere theoretically with what is known about the way biological systems work. Like other versions of traditional medicine or like sympathetic magic, TCM is a non-scientific social practice. But despite its not being scientific, its degree of empirical success, albeit comparatively very scant, is not zero. This is why TCM has survived for so long as a social institution, but this is also why that cultural archaism (Bueno, 1971) is entirely replaceable by WM in our world today. The educational repercussion of this final note resonates aloud here: TCM and the biological ontologies it is associated with should find accordingly no place in our educational system.

Data availability Not applicable.

Code availability Not applicable.

\section{Declarations}

Competing interests The authors declare no conflict of interest.

\section{References}

Ahn, A. C., et al. (2008). Electrical properties of acupunture points and meridians: A systhematic review. Bioelectromagnetics, 29(4), 245-256.

Akpinar, R., \& Kataray, S. (2018). Positive effects of acupuncture on atopic dermatitis. Int J Aller Medications., 4, 2.

Aramesh, K. (2018). Science and pseudoscience in traditional Iranian medicine. Archives of Iranian Medicine, 21(7), 315-323.

Ayer, A. J. (1936). Language, Truth and Logic. Victor Gollancz.

Bueno, G. (1971): Etnología y utopía. Valencia. Azanca.

Bueno, G. (1993). Medicina, magia y milagro. El Basilisco, 14, 3-38.

Bunge, M. (1982). Demarcating science from pseudo-science. Fundamenta Scientiae, 3, 369-388.

Bunge, M. (1985). Seudociencia e ideología. Alianza Editorial.

Bunge, M. (1991). What is Science? Does it matter to distinguish it from pseudoscience? A reply to my commentators. New Ideas in Psychology, 9(2), 245-283. 
Bunge. M. (1998): Philosophy of Science. Vol 1. From problem to theory. New Brunswick and London: Transaction Publishers.

Bunge, M. (2013). Medical Philosophy. Conceptual Issues in Medicine. Singapore.

Cannon, W. B. (1942). Vodoo Death. American Anthropologist, 44, 169-181.

Carnap, R. (1936). Testability and meaning. Philosophy of Science, 3(4), 419-471.

Cartwright, N. (2007). Are RCTs the gold standard. BioSocieties, 2(1), 11-20.

Cartwright, N. (2011). A philosopher's view on the long road from RCTs to effectiveness. Perspectives The art of medicine, 377(9775), 1400-1.

Challis, G. B., \& Stam, H. J. (1990). The spontaneous regression of cancer: A review of cases from 1900 to 1987. Acta Oncologica, 29(5), 445-450.

Cieri, F and Esposito, R. (2019): "Psychoanalysis and neuroscience: The bridge between mind and brain". Front Psychol. 10.

Cole, W. (1976). Spontaneous remission of cancer and the importance of finding its cause. National Cancer Institute Monograph, 44, 5-9.

Colquhoun, D., \& Novella, S. (2013). Acupunture is a theatrical placebo: The end of a myth. Anesthesia and Analgesia, 116(6), 1360-1363.

De Regt, H.W and Gijsbers, V. (2017): How false theories can yield genuine understanding. In Grimm, S, Baumberger, C and Ammon, S (eds). Explaining Understading. New Perspectives from Epistemology and Philosophy of Science. New York: Routledge.

Duhem, P. (1914): La théorie physique.son objecte et sa structure. Chevalier et Riviére: Paris.

Dupré, J. (1993). The disorder of things. Metaphysical foundations of the disunity of science. Harvard University Press.

Eigenschenk, M., et al. (2020). A critical examination of the main premises of Chinese Traditional Medicine. Wiener Klinische Wochenschrift., 132, 260-273.

Ernst, E. (2006). Acupuncture: A critical analysis. Journal of Internal Medicine., 259(2), 125-137.

Everson, T., \& Cole, W. (1968). Spontaneous remission of cancer. JB Saunder.

Fava, G. A., \& Sovino, N. (2000). Psychosomatic medicine: Emerging trends and perspectives. Psychother Psychosom, 29(4), 184-197.

Fava, G. A., \& Sovino, N. (2010). Psychosomatic medicine. The International Journal of Clinical Practice, 64(8), 1155-1161.

Feldman, R., \& Conee, E. (1985). Evidentialism. Philosophical Studies An International Journal for Philosophy in the Analytical Tradition, 48(1), 1534.

Fernandez Beanato, Damian. (2020). The multicriterial approach to the problem of demarcation. Journal for General Philosophy of Science., 51, 375-90.

Fisher, R. A. (1922). On the mathematical foundations of statistical analysis. Philos Trans Roy Soc London., $222,309-368$.

Fuller, S. W. (1985). The demarcation of science: A problem whose demise has been greatly exaggerated. Pacific Philosophical Quarterly, 66, 329-341.

Gaw, A. C., et al. (1975). "Efficacy of acupuncture on osteoarthritic pain: a controlled, double blind study. New England J Med, 293, 375-8.

Hacking, I. (1965). Logic of statistical inference. Cambridge University Press.

Hanson, N. R. (1958). Patterns of discovery: An inquiry into the conceptual foundations of science. Cambridge University Press.

Hansson, S.O. (1983): Vetenskap och ovetenskap, Stockholm: Tiden.

Hansson, S. O. (2009a). Cutting the Gordian Knot of Demarcation. International Studies in the Philosophy of Science., 23(3), 237-243.

Hansson, S.O. (2009b): "Philosophy of medical technology" in: Mejiers, A (ed) Handbook of the Philosophy of Science vol 9: Philosophy of Technology and Engineering sciences. Elsevier. 1275-1300.

Hansson, S.O. (2017): "Science and pseudo-science". The Stanford Encyclopedia of Philosophy (Summer 2017 Edition), Edward N. Zalta (ed.), URL = <https://plato.stanford.edu/archives/sum2017/entries/ pseudo-science/>.

Hard to Swallow. (2007). Nature. 448: 106

Hempel, C. (1950). Problems and changes in the empiricist criterion of meaning". Revue Internationale De Philosophie, 4, 41-63.

Hempel, C. (1965). Aspects of Scientific Explanation and Other Essays in the Philosophy of Science. Free Press.

Ingarden, R. (2018). "The logical attempt at a new formulation of philosophy: A critical remark", translated by Bernard Linsky. Journal for the History of Analytical Philosophy, 6(6), 2018.

Ioannidis, J. (2020). Política sanintaria basada en la falta de evidencia. In Camprubí, L (ed). La Sociedad entre pandemias. Madrid. Fundación Gaspar Casal. In press. 
James, P. B., et al. (2018). Traditional, complementary and alternative medicine in Sub-Saharan Africa: A systematic review. BMJ Global Health, 3, 5.

Kang, S., et al. (2018). Acupuncture improves symptoms in patients with mild-to-moderate atopic dermatitis: A randomized, sham-controlled, preliminary trial. Complementary Therapies in Medicine, 41, 90-98.

Keji, Ch., \& Hao, Xu. (2003). The integration of traditional Chinese medicine and western medicine. European Review, 11(2), 225-235.

Kitcher, P. (1982). Abusing Science. MIT Press.

Laudan, L. (1981). The pseudoscience of science. Philosophy of the Social Sciences, 11(2), 173-198.

Laudan, L. (1983): "The demise of the demarcation problem". In Cohen, R.S and Laudan. L. (eds). Physics, Philosophy and Psychoanalysis: Essays in honor of Adolf Grünbaum. Dordrecht: D. Reidel.

Lakatos, I. (1978). The methodology of scientific research programmes. Cambridge University Press.

Lakatos, I. (1981): Science and pseudoscience. In Brown, S et al (eds). Conceptions of Inquiry: a reader. London: Methuen.

Langevin, H. M., \& Yandow, J. A. (2002). Relationship of acupuncture points and meridians to connective tissue planes. Anatomical Record, 269(6), 257-265.

$\mathrm{Li}$, J et al (2020: "Effectiveness and safety of acupuncture for migraine: An overview of systematic reviews". Pain Res Manag vol 2020.

Lombrozo, T and Vasilyeva, N. (2017): Causal explanation. In Waldman, M. The Oxford handbook of causal reasoning. New York: Oxford University Press.

Lyketsos, G.C et al (2006): Psychosomatic medicine: A new psychiatric subspecialty in the US focused on the interface between psychiatry and medicine. Eur J Psychiat 20(3).

Mahner, M. (2013): "Science and pseudoscience: How to demarcate the (alleged) demise of the demarcation problem". In Piggliuci, M and Boudry, M. (eds). Philosophy of Pseudoscience. Reconsidering the demarcation problem. Chicago: Chicago University Press.

Mahomoodally, M. F. (2013). Traditional medicines in Africa An appraisal of ten potent African medical plants. Evid Based Complement Alternat Med, 2, 617459.

Masic, I., Miokovic, M., \& Muhamedagic, B. (2008). Evidence based medicine New approaches and challenges. Acta Inform Med, 16(4), 219-25.

Matuk, C. (2006). Seeing the body: The divergence of ancient Chinese and western medical illustration. $J B C, 32(1), 1-8$.

Matthews, M. R. (2019). Feng Shui: Teaching about science and pseudoscience. Springer.

McCain, K. (2014). Evidentialism and epistemic justification. Routledge.

Mendeson, G., et al. (1983). Acupuncture treatment of chronic back pain: A double-blind-placebo-controlled trial. American Journal of Medicine, 74(1), 49-55.

Merton, R. K. (1942). Science and technology in a democratic order. Journal of Legal and Political Philosophy., 1, 115-126.

Merton, R. K. (1973). The sociology of science. Theoretical and Empirical Investigations. Chicago.

Northoff, G. (2012). Psychoanalysis and the Brain: Why did Freud abandon neuroscience. Frontiers in Psychology, 3(71), 71.

Oliver, S. J. (2013). The role of traditional medicine practice in primary health care within Aboriginal Australia: A review of the literature. Journal of Ethnobiology and Ethnomedicine, 9, 46.

Ongay de Felipe, I. (2020): "Biological individuality and the extended evolutionary synthesis. A philosophical conundrum in a (new) biological focus". Filozofia Nauki, 28(3), 25-45.

Pigliucci, M. (2002). Species as family resemblance concepts: The (di)solution of the. Species concept? BioEssays, 25(6), 596-602.

Pigliucci, M. (2013). The demarcation problem: A (belated) response to Laudan. In M. Pigliucci \& M. Boudry (Eds.), Philosophy of pseudoscience. Reconsidering the demarcation problem. Chicago University Press.

Pigliucci, M., \& Boudry, M. (2013). Why the demarcation problem matters. In M. Pigliucci \& M. Boudry (Eds.), Philosophy of pseudoscience. Reconsidering the demarcation problem. Chicago University Press.

Popper, K. (1957). The poverty of historicism. Routledge.

Popper, K. (1959). The logic of scientific discovery. Hutchinson.

Popper, K. (1963). Conjectures and refutations. The growth of scientific knowledge. Routledge.

Popper, K. (1972). Objective knowledge: An evolutionary approach. Clarendon Press.

Popper, K. (1974a). Intellectual autobiography. In P. A. Schilpp (Ed.), The philosophy of Karl Popper (pp. 3-118). Open Court.

Popper, K. (1974b): "Replies to my Critics", in Schilpp, PA (ed): The philosophy of Karl Popper vol 2. La Salle, Il: Open Court. 3-118. 961-1197 
Quine, W. V. (1951). Main trends in recent philosophy: Two dogmas of empiricism. The Philosophical Review, 60(1), 20-43.

Rudner, R. (1953). The scientist quae scientist makes value judgments. Philosophy of Science., 20(1), 1-16.

Ruse, M. (ed) (1996): But is it science? The philosophical question in the creation/evolution controversy, Amherst, NY: Prometheus Books.

Sackett, D. L. (1997). Evidence-based medicine. Semin Perinatal, 21(1), 3-5.

Salmon, W. (1984). Scientific explanation and the causal structure of the world. Princeton University Press.

Scheid, V. (1999). The globalization of Chinese medicine. The Lancet., 354, 10.

Schlick, M. (1936). Meaning and verification. Philosophical Review, 45, 339-368.

Sober, E. (1999). Philosophy of biology. Westview Press.

Talvitie, V. (2009). Freudian unconscious and cognitive neuroscience: From unconscious fantasies to neural algorithms. Karnac.

Vits, S., et al. (2011). Behavioral conditioning as the mediator of placebo responses in the immune system. Philos Trans R Soc London Bio Sci, 366(1572), 1799-1807.

Sternberg, E. (2002). Walter B Cannon and Voodo Death: A perspective from 60 years on. American Journal of Public Health, 92(10), 1564-1566.

Vase, L (2015): "Can acupuncture treatment be double-minded? An evaluation of double -blind acupuncture treatment of postoperative pain" Plose One 10 (13).

Vos, R., \& Willems, D. L. (2000). Technology in medicine: Ontology, epistemology, ethics and social philosophy at the crossroads. Theor Med Biotech, 21(1), 1-7.

Woodward, J. (2003). Making things happen: A theory of causal explanation. Oxford University Press.

Yang, M. et al (2020): "Acupuncture for menstrual migraine: A systematic review" BMJ Supportive and Palliative Care. o. 1-11.

Publisher's Note Springer Nature remains neutral with regard to jurisdictional claims in published maps and institutional affiliations. 